\title{
Embolisation of pulmonary arteriovenous malformations: results and follow up in 32 patients
}

\author{
T J Haitjema, T Th C Overtoom, C J J Westermann, J W J Lammers
}

\begin{abstract}
Background - Pulmonary arteriovenous malformations may cause a number of complications when left untreated. Embolisation of the feeding vessels is a relatively new approach and information concerning its efficacy and long term results is scarce.

Methods - Pulmonary arteriovenous malformations with feeding arteries of $>3 \mathbf{~ m m}$ were treated by embolisation. Right to left shunt fraction and arterial oxygen pressure breathing air $\left(\mathrm{PaO}_{2}\right)$ were measured before and after treatment. Six monthly measurement of shunt fraction was used for follow up.

Results - In 32 patients 92 pulmonary arteriovenous malformations were treated by coil embolisation. Mean shunt fraction decreased from $16 \cdot 6 \%$ to $7 \cdot 4 \%$ and $\mathrm{PaO}_{2}$ increased from $9.6 \mathrm{kPa}$ to $11.5 \mathrm{kPa}$. Treatment was incomplete in two patients, one of whom was subsequently treated surgically. Serious complications occurred in one patient. Recanalisation of embolised vessels occurred in two cases after 22 and 28 months, respectively. Mean period of follow up was 25 months.

Conclusions - Embolisation is a safe and efficacious treatment for most pulmonary arteriovenous malformations. Long term studies are necessary to determine the risk of recanalisation.

(Thorax 1995;50:719-723)
\end{abstract}

Department

of Pulmonology

T J Haitjema

C J J Westermann

Department

of Radiology

$\mathrm{T}$ Th C Overtoom

St Antonius Hospital, 3435 CM Nieuwegein, The Netherlands

Department of Pulmonology, University Hospital Utrecht,

The Netherlands

J W J Lammers

Reprint requests to: Dr C J J Westermann.

Received 22 September 1994

Returned to authors

5 January 1995

5 January 1995 recived

30 January 1995

30 January 1995
Accepted for publication

2 February 1995
Keywords: pulmonary arteriovenous malformation, embolisation.

Pulmonary arteriovenous malformations are rare, mostly congenital, abnormalities of pulmonary circulation, often associated with hereditary haemorrhagic telangiectasia (HHT). They are direct communications between pulmonary arteries and veins via enlarged, tortuous vascular spaces. ${ }^{1-3}$ The right to left shunt causes hypoxaemia which may give rise to decreased exercise capacity, dyspnoea and cyanosis. Pulmonary arteriovenous malformations can cause two different types of complications: (1) bleeding from the abnormal vessels causing haemoptysis or a haemothorax, both of which are potentially fatal; and (2) interruption of the capillary filter of the lung so that emboli, normally trapped in the pulmonary capillaries, can enter the systemic circulation via the pulmonary arteriovenous malformations. ${ }^{4}$ Thrombi arising in the malformation itself may also cause sys- temic emboli. ${ }^{5}$ Thus, up to $56 \%$ of patients with pulmonary arteriovenous malformations report a history of stroke or transient ischaemic attack. $^{6-8}$ Brain abscess occurs in $5-14 \%$ of patients with a pulmonary arteriovenous malformation as a result of septic emboli. 4910

It is generally accepted that these risks justify treatment of pulmonary arteriovenous malformations, even when asymptomatic, if the diameter of the feeding vessels is more than $3 \mathrm{~mm} .{ }^{11}$ Disadvantages of surgical treatment are loss of normal lung tissue surrounding the pulmonary arteriovenous malformations and morbidity associated with thoracotomy. Nowadays, embolisation of the feeding vessel(s) with silicone balloons or metal coils is an accepted mode of treatment ${ }^{12-14}$ and usually eliminates the need for thoracotomy. Whether coils or balloons are superior has not yet been studied and still depends on personal preference and experience. ${ }^{15}$ Advantages and disadvantages of both methods have been reviewed elsewhere. ${ }^{15}$ In a recent series from a large thoracic unit the complications of balloon embolisation led the authors to conclude that "conservative surgical resection remains the treatment of choice". ${ }^{10}$

Although many reports concerning embolisation of pulmonary arteriovenous malformations have been published, data on long term results are limited. We therefore present our long term results of treatment of pulmonary arteriovenous malformations by embolisation.

\section{Methods}

Thirty two patients with pulmonary arteriovenous malformations have been treated with embolisation during the last five years, 31 of whom had HHT. Fifteen patients were found during a screening programme involving family members of patients with HHT. Nineteen of the 31 patients had multiple pulmonary arteriovenous malformations. Three had undergone surgery prior to embolisation and were treated for new or enlarging pulmonary arteriovenous malformations; all three had HHT. The signs and symptoms caused by the pulmonary arteriovenous malformations are listed in table 1. Ten patients were asymptomatic.

Before and after embolisation arterial oxygen tension breathing air $\left(\mathrm{PaO}_{2}\right)$ and right to left shunt were measured in all patients while semirecumbent. The $100 \%$ oxygen method was used to calculate the shunt fraction, ${ }^{16}$ values of $<5 \%$ being considered normal. Every six months chest radiography, $\mathrm{PaO}_{2}$, and right to left shunt were measured for follow up. ${ }^{17}$ In 
Table 1 Signs and symptoms in patients with pulmonary arteriovenous malformations $(n=32)$

\begin{tabular}{lc}
\hline Male:female & $9: 23$ \\
Mean (range) age (years) & $36(14-71)$ \\
Exercise intolerance $_{\text {Hypoxaemia }}{ }^{2}$ & $17(53 \%)$ \\
Cyanosis & $32(100 \%)$ \\
Clubbing & $6(19 \%)$ \\
Haemoptysis & $2(6 \%)$ \\
Metastatic abscesses & $2(6 \%)$ \\
Previous stroke or transient & $2(6 \%)$ \\
ischaemic attack & $4(13 \%)$ \\
\hline
\end{tabular}

${ }^{a}$ Arterial oxygen tension $\left(\mathrm{PaO}_{2}\right)<(104-0.24 \times$ age $) / 7.5 \mathrm{kPa}{ }^{28}$

case of rising shunt fraction intravenous digital substraction angiography of the pulmonary arteries was performed. The paired $t$ test was used to analyse the difference in values of $\mathrm{PaO}_{2}$ and shunt fraction before and after treatment. Cases with missing values were excluded from the analysis.

\section{EMBOLISATION TECHNIQUE}

Embolisation was performed by the same radiologist in all patients (TO). Following introduction via the femoral vein, pulmonary angiography was performed using the digital substraction technique. ${ }^{17}$ Feeding vessels with a diameter of more than $3 \mathrm{~mm}$ were selectively cannulated and embolised with coils of appropriate size. Additional coils were placed until flow through the pulmonary arteriovenous malformations was completely absent (fig 1). In two patients with high flow pulmonary arteriovenous malformations a catheter with an occlusion balloon was used to interrupt blood flow in the feeding artery during embolisation in order to prevent paradoxical embolisation of the coils. In one patient a detachable balloon was used in combination with coils. All pulmonary arteriovenous malformations with accessible feeding vessels larger than $3 \mathrm{~mm}$ were embolised.

\section{Results}

Individual results of treatment are given in table 2. In 44 sessions 92 pulmonary arteriovenous malformations were embolised, 56 on the right and 36 on the left. Eighteen had a single feeding vessel (simple pulmonary arteriovenous malformation), 84 had more than one feeding vessel (complex pulmonary arteriovenous malformation). In five patients two procedures were necessary, in two patients three were required, and one patient needed four procedures. Embolisation was incomplete in two pulmonary arteriovenous malformations: one had a very short feeding vessel which precluded safe coil placement, and in the other the complex anatomy and angular branching of the multiple feeding vessels precluded complete embolisation in one session. The first patient underwent surgery; in the second another procedure was proposed but declined by the patient.

Mean (SD) $\mathrm{PaO}_{2}$ increased from $9.6(1 \cdot 7)$ $\mathrm{kPa}$ to $11.5(1.7) \mathrm{kPa}(\mathrm{p}<0.001)$; mean (SD) shunt fraction decreased from $16.6 \%(7 \cdot 8 \%)$ to $7 \cdot 4 \%(5 \cdot 1 \%)(p<0 \cdot 001)$. Excluding the two patients in whom embolisation failed, mean $\mathrm{PaO}_{2}$ rose from $9.6 \mathrm{kPa}$ to $11.7 \mathrm{kPa}$ and mean shunt fraction decreased from $16 \cdot 3 \%$ to $6 \cdot 7 \%$. In eight patients with HHT a shunt of more than $10 \%$ persisted due to the existence of multiple pulmonary arteriovenous malformations too small to embolise. During follow up the shunt fractions in these patients remained stable.

Table 2 Results of embolisation in individual patients $(n=32)$

\begin{tabular}{|c|c|c|c|c|c|c|c|c|}
\hline \multirow{2}{*}{$\begin{array}{l}\text { Patient } \\
\text { no. }\end{array}$} & \multicolumn{2}{|c|}{ No. of PAVMs treated } & \multirow{2}{*}{$\begin{array}{l}\text { No. of } \\
\text { sessions }\end{array}$} & \multirow{2}{*}{$\begin{array}{l}\text { Shunt before } \\
\text { treatment (\%) }\end{array}$} & \multirow{2}{*}{$\begin{array}{l}\text { Shunt after } \\
\text { treatment }(\%)^{a}\end{array}$} & \multirow{2}{*}{$\begin{array}{l}\mathrm{PaO}_{2} \text { before } \\
\text { treatment }(\mathrm{kPa})\end{array}$} & \multirow{2}{*}{$\begin{array}{l}\mathrm{PaO}_{2} \text { after } \\
\text { treatment }(\mathrm{kPa})^{a}\end{array}$} & \multirow{2}{*}{$\begin{array}{l}\text { Follow up } \\
\text { (months) }\end{array}$} \\
\hline & $R$ & $L$ & & & & & & \\
\hline 1 & 1 & & 1 & 8 & $5 \cdot 5$ & $10 \cdot 6$ & $10 \cdot 6$ & 38 \\
\hline $2^{\mathrm{b}}$ & & 1 & 2 & $12 \cdot 7$ & $5 \cdot 5$ & 10.9 & $13 \cdot 2$ & 35 \\
\hline 3 & 9 & 3 & 2 & 35 & 9 & $6 \cdot 3$ & $9 \cdot 3$ & 27 \\
\hline 4 & & 1 & 1 & 6.5 & 2.5 & $13 \cdot 2$ & $13 \cdot 1$ & 43 \\
\hline 5 & 6 & 2 & 3 & $27 \cdot 5$ & 18 & $6 \cdot 2$ & 9.5 & 39 \\
\hline $6^{c}$ & 1 & & 2 & 26 & 5 & $7 \cdot 0$ & $12 \cdot 4$ & 71 \\
\hline $7^{\mathrm{d}}$ & 1 & & 1 & $14 \cdot 5$ & $6 \cdot 5$ & $9 \cdot 7$ & $8 \cdot 2$ & 35 \\
\hline 8 & 2 & 4 & 4 & 27 & 13 & $6 \cdot 4$ & $10 \cdot 0$ & 43 \\
\hline 9 & & 1 & 1 & 9 & 6 & $9 \cdot 7$ & $10 \cdot 1$ & 32 \\
\hline 10 & 2 & 1 & 1 & $23 \cdot 5$ & 1.5 & $8 \cdot 3$ & $13 \cdot 2$ & 34 \\
\hline 11 & 4 & 1 & 2 & 18 & 3.5 & $7 \cdot 5$ & $11 \cdot 2$ & 20 \\
\hline 12 & 7 & 8 & 3 & 25 & $14 \cdot 5$ & $8 \cdot 0$ & $9 \cdot 5$ & 43 \\
\hline 13 & 1 & 2 & 1 & 12.5 & 6.5 & $10 \cdot 1$ & 10.6 & 40 \\
\hline 14 & 2 & & 1 & $12 \cdot 6$ & 6 & $10 \cdot 8$ & $12 \cdot 5$ & 31 \\
\hline 15 & 2 & & 1 & 13 & 2 & 10.0 & 17.0 & 29 \\
\hline 16 & & 1 & 1 & $15 \cdot 3$ & 4 & $9 \cdot 2$ & $11 \cdot 4$ & 13 \\
\hline 17 & 4 & 4 & 1 & $24 \cdot 5$ & 11.5 & $7 \cdot \overline{8}$ & $10 \cdot 3$ & 11 \\
\hline 18 & 1 & 1 & 1 & 8 & 3 & $12 \cdot 0$ & 12.9 & 11 \\
\hline $19^{c}$ & & 1 & 1 & 25 & 20.5 & $8 \cdot 1$ & 8.8 & 9 \\
\hline $20^{c}$ & 1 & & 1 & 16.5 & $14 \cdot 7$ & $9 \cdot 2$ & 10.0 & 10 \\
\hline 21 & 1 & & 1 & 9 & $8 \cdot 2$ & $9 \cdot 4$ & $11 \cdot 2$ & 11 \\
\hline 22 & $i$ & 1 & 1 & 7 & 2 & $11 \cdot 3$ & 13.2 & 11 \\
\hline 23 & & 1 & 1 & 17 & 6.5 & 10.0 & 12.3 & 11 \\
\hline 24 & 1 & & 1 & 8.5 & 1.5 & 10.5 & 11.8 & 8 \\
\hline 25 & 1 & & 1 & $17 \cdot 5$ & 8.5 & 11.6 & $12 \cdot 9$ & 8 \\
\hline 26 & 1 & 1 & 1 & 11 & $4 \cdot 5$ & 10.9 & ND & 5 \\
\hline 27 & 1 & & 1 & ND & 3 & $12 \cdot 2$ & $12 \cdot 8$ & 5 \\
\hline 28 & 2 & 1 & 1 & $25 \cdot 5$ & 16.5 & $7 \cdot 8$ & $11 \cdot 1$ & 5 \\
\hline 29 & & 1 & 1 & 19 & 4 & $10 \cdot 1$ & $12 \cdot 2$ & 3 \\
\hline 30 & 1 & & 1 & 3.5 & ND & 11.6 & 12.6 & 2 \\
\hline 31 & 1 & & 1 & 20 & 5.5 & 9.9 & $12 \cdot 3$ & 2 \\
\hline 32 & 2 & & 2 & 15 & 10.5 & $10 \cdot 3$ & $10 \cdot 8$ & 8 \\
\hline
\end{tabular}

PAVM = pulmonary arteriovenous malformation; $\mathrm{PaO}_{2}=$ arterial oxygen tension; $\mathrm{ND}=$ not done. PAVM $=$ pulmonary arteriovenous malformation; $\mathrm{PaO}_{2}=$ arterial oxygen tension; $\mathrm{ND}=$ not done.
a Most recent value; ${ }^{b}$ recanalisation 22 months after embolisation; ${ }^{c}$ recanalisation 28 months after embolisation; ${ }^{d}$ patient without hereditary haemorrhagic telangiectasia; ${ }^{\mathrm{C}}$ treatment incomplete. 
A

B

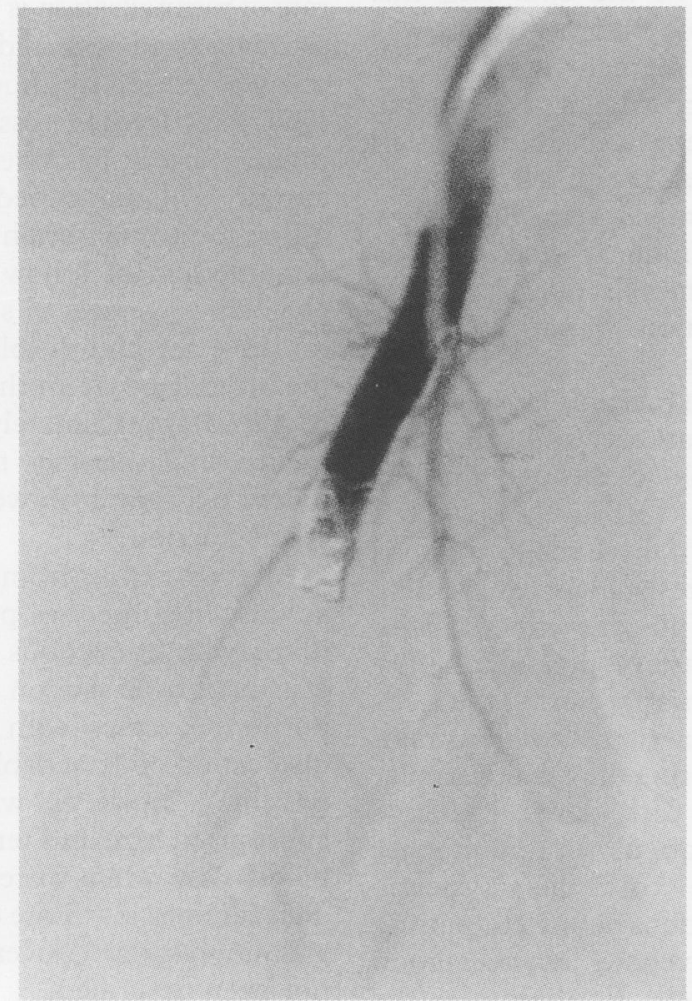

Figure 1 Pulmonary arteriovenous malformation (A) before and (B) after coil embolisation.

Complications were seen in eight of 44 procedures $(18 \%)$ and consisted of an arrhythmia in one patient, hyperventilation in one, pleurisy after the procedure in four, and dislocation of a coil in two patients. The two dislocated coils were retrieved from the left ventricle using a catheter forceps. In patient no. 32, who had large pulmonary and hepatic arteriovenous malformations, several complications occurred. Complete occlusion of the pulmonary arteriovenous malformations was achieved with

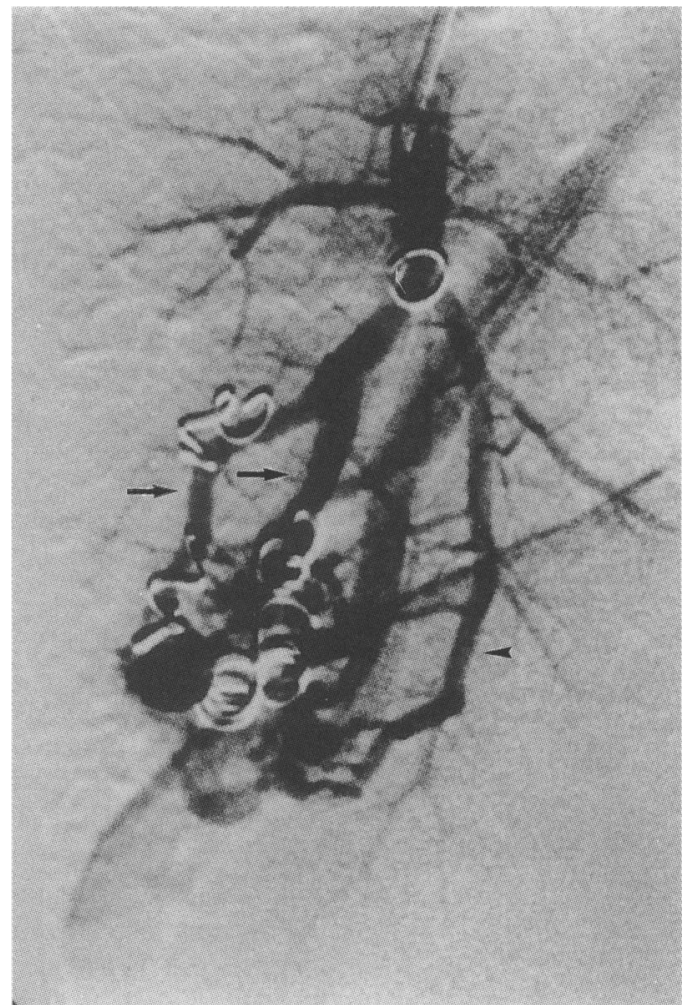

Figure 2 Recanalisation of embolised feeding vessels (arrows) and appearance of a new feeding vessel (arrow head).

coils and a balloon. A dislocated coil was retrieved from the left ventricle. After two days the balloon had deflated spontaneously and migrated to the hepatic pulmonary arteriovenous malformation. Six weeks later a haemopericardium developed, probably due to cardiac perforation during retrieval of the coil from the left ventricle. Subsequently she was found to have pulmonary hypertension which was not present before embolisation of two large distal pulmonary arteriovenous malformations.

The mean period of follow up was $24 \cdot 7$ (range 1-72) months. There were 14 patients with a follow up period of over two years with a mean follow up of 40 months. In two patients recanalisation of the occluded vessel occurred 22 and 28 months after embolisation, respectively. In both cases an increased shunt fraction was noted. In one recanalisation was, in retrospect, due to the use of coils of the wrong type placed early in our unit's experience. These coils were too large and not sufficiently coiled up in the lumen of the vessel (fig 2). In the second case there was recanalisation of embolised vessels and appearance of new feeding vessels. Both pulmonary arteriovenous malformations were re-embolised successfully.

\section{Discussion}

The symptoms caused by pulmonary arteriovenous malformations in our patients are in line with those reported in the literature, although the rate of previous stroke or transient ischaemic attack is low; rates of $5-56 \%$ have been described. ${ }^{681819}$ This is perhaps due to 
the fact that 15 of the 32 patients were identified during a screening programme in families with HHT. Paradoxical embolisation of septic material resulted in metastatic abscesses in kidney and knee in one patient and in a brain abscess in another before the diagnosis of pulmonary arteriovenous malformation was made. All our patients were hypoxaemic at rest, although in many this was mild. Unless strictly normal values are adhered to, hypoxaemia can easily be overlooked. In view of the shape of the oxygen dissociation curve it is therefore not advisable to rely on oxygen saturation alone in, for example, transcutaneous oximetry, as a diagnostic tool or in follow up after embolisation.

Embolisation can be time consuming, especially with complex pulmonary arteriovenous malformations or if more than one malformation is present. Multiple sessions were necessary in eight patients; one patient refused a second procedure. Others have also reported that more than one session may be needed for complete occlusion. ${ }^{820}$ Embolisation of one pulmonary arteriovenous malformation failed due to the presence of a very short feeding vessel; placing a coil in an unstable position would risk dislocation of the coil, and this pulmonary arteriovenous malformation was successfully resected by segmentectomy.

Dislocation of a coil occurred in two patients, both of which were retrieved from the left ventricle. These incidents prompted us to use an occlusion balloon to interrupt the blood flow through rapid flow pulmonary arteriovenous malformations during embolisation.

The serious complications in patient no. 32 were probably due to a high cardiac output caused by the presence of multiple large hepatic arteriovenous malformations and shunting of a large amount of blood through the low resistance pulmonary arteriovenous malformations. On closure of these malformations the pulmonary vascular resistance rose, leading to right heart failure. Thus, we would advise measuring pulmonary artery pressure before embolisation, and temporarily closing the feeding vessel of the pulmonary arteriovenous malformations while monitoring the cardiovascular response in patients with large systemic arteriovenous malformations or pulmonary hypertension. Closure of the systemic arteriovenous malformations before embolising the pulmonary arteriovenous malformation could also be considered. Furthermore, the central venous oxygen content is raised in these patients due to the left to right shunt. As venous oxygen content is usually estimated in the calculation of the shunt fraction with the $100 \%$ oxygen technique, this method is bound to be inaccurate in this situation.

The incidence of pleurisy after coil embolisation in our series $(11 \%)$ is comparable to that in series using balloon embolisation. ${ }^{8}$ Assuming that pleurisy is the result of infarction due to occlusion of normal branches of the pulmonary artery, we cannot support the statement that balloon embolisation is superior in preventing occlusion of these normal branches. ${ }^{8}$
Five series from two institutions have reported their results of embolisation. ${ }^{819-22}$ Other reported series have not presented their results in terms of improvement of gas exchange. ${ }^{2324}$ With respect to reduction of shunt fraction and hypoxaemia, our data compare favourably with previous reports using either coil (16 patients) ${ }^{19}$ or balloon (76 patients) ${ }^{8}$ embolisation. The shunt fraction decreased from $28 \cdot 1 \%$ to $13 \%$ in the former, and $\mathrm{PaO}_{2}$ increased from $7 \cdot 3$ to $9.5 \mathrm{kPa}$ in the latter. The pre-embolisation values of shunt and $\mathrm{PaO}_{2}$ in our patients suggest less severe disease, probably because part of our population was found during screening of asymptomatic family members of patients with HHT.

Long term results are limited to only two reports; in one study nine patients had stable oxygen saturations on regular arterial blood gas analysis for a mean period of 26 (10-46) months. ${ }^{20}$ The second study reported constant serial values of arterial blood gas measurements over five years, but did not state the number of patients involved. ${ }^{8}$ No recanalisation of embolised vessels was reported. However, recanalisation occurs after embolisation both with balloons ${ }^{10}$ and with coils. ${ }^{25}$ The estimated rate of recanalisation is $5-10 \% .{ }^{1126}$ In our series recanalisation occurred in two patients, and in one was caused by choosing coils of the wrong type. New feeding vessels from either the pulmonary artery or systemic arteries ${ }^{23}$ may also appear. This happened in one patient, in addition to recanalisation of an embolised vessel. Our method of follow up may identify more recanalised vessels as shunt fraction is a more sensitive method of follow up than measuring the arterial $\mathrm{Po}_{2}{ }^{27}$ Both cases of recanalisation occurred approximately two years after treatment, which stresses the need for long term follow up, and both were detected by a rising shunt fraction.

A recent report from a thoracic surgical unit advocated surgery as primary therapy for pulmonary arteriovenous malformations. ${ }^{10}$ This was mainly based on a relatively large proportion of cases with delayed deflation and dislocation of detachable balloons (three of five patients). However, with the use of coils of appropriate size and temporary interruption of blood flow when necessary, the risk of early dislocation is low. Late dislocation of coils from a pulmonary arteriovenous malformation has not been described.

In conclusion, embolisation of pulmonary arteriovenous malformations has been shown to be a safe and efficacious method of treatment. In view of the risk of deflation and subsequent migration of balloons described in the literature ${ }^{10}$ and experienced in one of our patients, we prefer to use coils. Resection has to be considered when vascular anatomy precludes embolisation. Blood flow through pulmonary arteriovenous malformations can be interrupted during the procedure to prevent paradoxical embolisation of the coils. Pulmonary hypertension can develop in patients with a coexisting large systemic left to right shunt. 
This study was supported by grants from the Bakhuys Roozeboom Foundation and the Martina de Beukelaar Foundation.

1 Sluiter-Eringa H, Orie NGM, Sluiter JH. Pulmonary arteriovenous fistula. Diagnosis and prognosis in non-compliant patients. Am Rev Respir Dis 1969;100:177-88.

2 Dines DE, Seward JB, Bernatz PE. Pulmonary arteriovenous fistulas. Mayo Clin Proc 1983;58:176-81.

3 Mansour KA, Hatcher CR, Logan WD, Abbott OA. Pulmonary arteriovenous fistula. Am Surgeon 1971;37:203-8.

4 Press OW, Ramsey PG. Central nervous system infections associated with hereditary hemorrhagic telangiectasia. $A m$ f Med 1984;77:86-92.

5 Hewes RC, Auster M, White RI. Cerebral embolism - first manifestation of pulmonary arteriovenous malformation in patients with hereditary hemorrhagic telangiectasia. in patients with hereditary hemorrhagic

6 Dines DE, Arms RA, Bernatz PE, Gomes MR. Pulmonary arteriovenous fistulas. Mayo Clin Proc 1974;49:460-5.

7 Román G, Fisher M, Perl DP. Poser CM. Neurologica manifestations of hereditary hemorrhagic telangiectasia (Rendu-Osler-Weber disease): report of two cases and review of the literature. Ann Neurol 1978;4:130-44.

8 White RI, Lynch-Nyhan A, Terry Pl, Buescher PC, Farmlett EJ, Charnas L, et al. Pulmonary arteriovenous malformations: techniques and long-term outcome of embolotherapy. Radiology 1988;169:663-9.

9 Tyler HR. Brain abscess and pulmonary arteriovenous fistula. Trans Neurol Assoc 1973;98:314-7.

10 Puskas JD, Allen MS, Moncure AC, Wain JC, Hilgenburg $\mathrm{AD}$, Wright $\mathrm{C}$, et al. Pulmonary arteriovenous malformations: therapeutic options. Ann Thorac Surg 1993, 56:253-8.

11 Burke CM, Safai C, Nelson DP, Raffin TA. Pulmonary arteriovenous malformations: a critical update. $\mathrm{Am} R e v$ Respir Dis 1986;134:334-9.

12 Taylor BG, Cocheril EM, Manfredi F, Klatte EC. Therapeutic embolization of the pulmonary artery in pulmonary peutic embolization of the pulmonary artery in pulm

13 White RI, Barth KH, Kaufman SL, Terry PB. Detachable silicone balloons: results of experimental study and clinical investigations in hereditary hemorrhagic telangiectasia. Ann Radiol 1980;23:338-40.

14 Gianturco C, Anderson JH, Wallace S. Mechanical device for arterial occlusion. Am $\mathcal{F}$ Roentgenol 1975;124:428-35.
15 Reidy JF. Embolization of arteriovenous malformations. In Dondelinger RF, Rossi P, Kurdziel JC, Wallace S, eds. Interventional radiology. New York. Thieme, 1990:513-7.

16 Cotes JE. Lung function. Assessment and application in medicine. 5th ed. Oxford: Blackwell Scientific Publications, 1993:253-5.

17 Feldman L. Digital substraction angiography of the lung. Clin Chest Med 1984;5:313-28.

18 Vase $P$, Holm $M$, Arendrup $H$. Pulmonary arteriovenous fistulas in hereditary hemorrhagic telangiestasia. Acta Med Scand 1985;218:105-9.

19 Jackson JE, Whyte MKB, Allison DJ, Hughes JMB. Coil embolization of pulmonary arteriovenous malformations. Cor Vasa 1990;32:191-6.

20 Hartnell GG, Jackson JE, Allison DJ. Coil embolization of pulmonary arteriovenous malformations. Cardiovasc Intervent Radiol 1990;13:347-50.

21 Hartnell GG, Allison DJ. Coil embolization in the treatment of pulmonary arteriovenous malformations. $\mathcal{f}$ Thorac Ima 989;4:81-5.

22 Terry PB, White RI, Barth KH, Kaufman SL, Mitchell SE. Pulmonary arteriovenous malformations. Physiologic observations and results of therapeutic balloon embolization. $N$ Engl f Med 1983;308:1197-200.

23 Remy J, Remy-Jardin M, Wattinne L, Deffontaines C. Pulmonary arteriovenous malformations: evaluation with CT of the chest before and after treatment. Radiology 1992; 182:809-16.

24 Goergen SK, Sacharias NR. Pulmonary arteriovenous malformations: pathology, clinical features and treatment with balloon and coil occlusion. Australas Radiol 1992;36:2229 .

25 Remy-Jardin M, Wattinne L, Remy J. Transcatheter oc clusion of pulmonary arterial circulation and collatera supply: failures, incidents and complications. Radiology 1991;180:699-705.

26 White RI, Pollak JS. Pulmonary arteriovenous malformations: diagnosis with three-dimensional helical CT - a breakthrough without contrast media (editorial). Radiology 1994;191:613-4.

27 Chilvers ER, Whyte MKB, Jackson JE, Allison DJ, Hughes JBM. Effect of percutaneous transcatheter embolization on pulmonary arteriovenous malformations. Am Rev Respir Dis 1990;142:420-5.

28 West JB. Pulmonary pathophysiology. 3rd edn. Baltimore Williams and Wilkins, 1987:204-5. 